\title{
Soil Water Infiltration Observation with Microwave Radiometers
}

\author{
Thomas J. Jackson, Senior Member, IEEE, Thomas J. Schmugge, Senior Member, IEEE, \\ Peggy E. O'Neill, Associate Member, IEEE, and Marc B. Parlange
}

\begin{abstract}
Experiments were conducted using truck-based microwave radiometers operating at 1.41 - (L-band) and $2.65-\mathbf{G H z}$ (S-band) horizontal polarization to observe small plots during and following sprinkler irrigation. These experiments were conducted on a sandy loam soil in 1994 and a silt loam in 1995. Sandy loam soils typically have higher infiltration capabilities than clays, and in our studies, we were not able to exceed this with the irrigation system. The observed brightness temperature $\left(T_{B}\right)$ quickly reached a nominally constant value during irrigation. When the irrigation was stopped, the $T_{B}$ began to increase as drainage took place. Contributing depth-related differences were observed for $L-$ and S-band as expected. The irrigation rates in 1995 with the silt loam soil exceeded the saturated conductivity of the soil. During irrigation, the $T_{B}$ values exhibited a phenomenon that had not been previously observed and identified and is associated with coherent interference. The L- and S-band exhibited similar patterns but were not identical due to contributing depth. These results suggested the existence of a sharp dielectric boundary (wet over dry soil) that was increasing in depth with time. The temporal description of the wetting front boundary was used with a coherent radiative transfer model to predict $T_{B}$ for $L$ - and S-band.
\end{abstract}

Index Terms-Microwave, radiometry, soil moisture.

\section{INTRODUCTION}

I NFILTRATION is the process of water entry into the soil from rainfall, irrigation, or snowmelt. It is interrelated with soil water movement and redistribution. These processes control surface runoff, evaporation, and erosion as well as critical water-quality transport phenomena. Point-scale infiltration modeling is well understood and can be modeled from basic physical laws. Extrapolating this theory spatially and determining the necessary soil characteristics remains a challenge. In this investigation, the role of remote sensing in infiltration studies is addressed. Remote sensing can provide a spatially integrated measurement that could play an important role in scaling. Of particular interest is microwave remote sensing.

The measurement provided by a microwave radiometer is the brightness temperature $\left(T_{B}\right)$. The $T_{B}$ of a surface can be approximated as emissivity multiplied by physical tempera-

Manuscript received October 6, 1997; revised April 10, 1998.

T. J. Jackson and T. J. Schmugge are with the USDA Agricultural Research Service Hydrology Laboratory, Beltsville, MD 20705 USA (e-mail: tjackson@hydrolab.arsusda.gov).

P. E. O'Neill is with the Hydrological Sciences Branch, NASA Goddard Space Flight Center, Greenbelt, MD 20771 USA.

M. B. Parlange is with the Department of Geography and Environmental Sciences, The Johns Hopkins University, Baltimore, MD 21218 USA.

Publisher Item Identifier S 0196-2892(98)06839-9. ture. If the physical temperature is estimated independently, emissivity can be determined. Emissivity can be related to the dielectric constant of the soil, which is a composite of the values of its components: air, soil particles, and water. Values of the real part of the dielectric constant for air and soil particles are one and five, respectively. Water has a value of about 80 at the longer wavelengths considered here $(>5 \mathrm{~cm})$. The basic reason microwave remote sensing is capable of providing soil moisture information is this large difference between water and the other components. Using a dielectric mixing model [1], [2], the volume fraction of water (soil moisture) can be estimated.

There are well-known theories describing the emission from a soil profile with uniform or varying properties [3]-[5]. The computations involve a nonlinear weighting that decays with depth. Some modeling studies have suggested that this dominant depth is $1 / 10$ the wavelength [4]. Field experiments [6] suggest that the contributing depth is about $1 / 4$ the wavelength (based on a wavelength range from 2 to $21 \mathrm{~cm}$ ).

Previous research focusing on the use of remote sensing and infiltration has been very limited [7], [8]. Several recent investigations have examined new approaches to estimating infiltration parameters that depend on temporal observations of soil moisture [9]-[11].

The work described here focuses on the results obtained in experiments using passive microwave radiometers installed on a truck-based observing platform. Unique aspects of these studies are the use of multifrequency microwave measurements, high temporal resolution (as compared with typical remote-sensing field observations), and a spatial resolution on the order of $2 \mathrm{~m}$

\section{S- AND L-BAND MicRowAVE RADIOMETER (SLMR) SYSTEM}

The S- and L-band Microwave Radiometer (SLMR) is a dual-frequency passive sensor system operating at S-band $(2.65 \mathrm{GHz}$ or $11.3 \mathrm{~cm})$ and L-band $(1.413 \mathrm{GHz}$ or $21.2 \mathrm{~cm})$. The radiometric sensitivity of each radiometer is $0.1 \mathrm{~K}$ for a 1 -s integration time. Each linearly polarized microstrip patch antenna is configured as a $4 \times 4$ phased array providing $20^{\circ}$ of beamwidth with a main beam efficiency of $97 \%$. The antenna and receiver are packaged together in a thermally controlled enclosure for each frequency. System software monitors the thermal status of the radiometers and attempts to maintain 


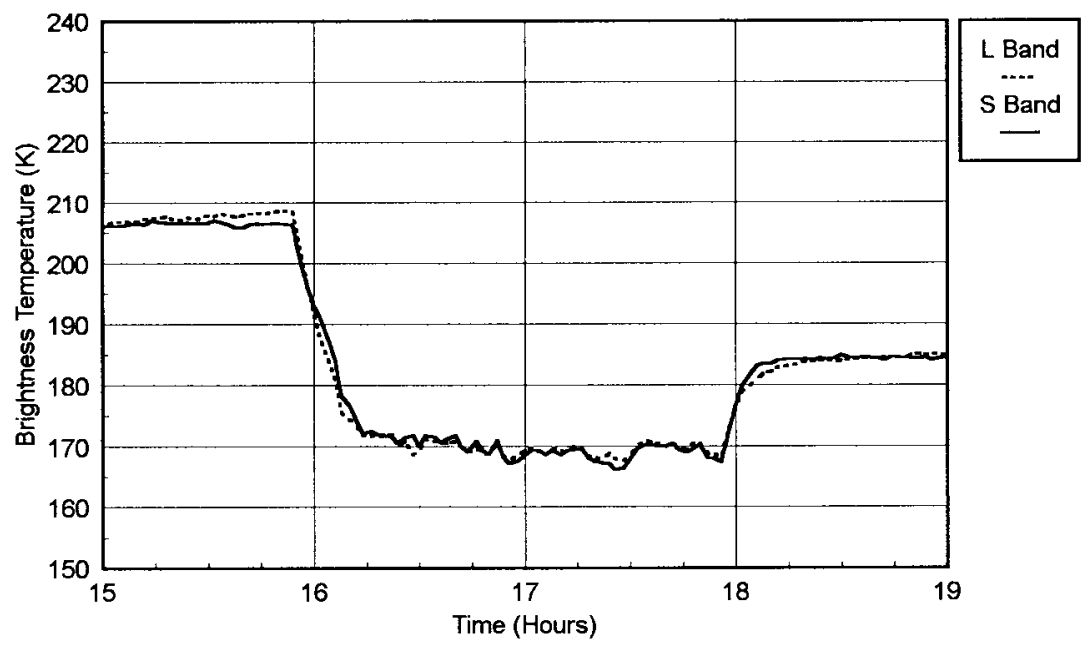

Fig. 1. Observed $\boldsymbol{T}_{\boldsymbol{B}}$ during and after infiltration on September 27, 1994, on a bare sandy loam soil at Beltsville.

thermal equilibrium at the defined goal temperature through the distributed heater network.

For the 1994 experiments, the SLMR system was mounted on a boom truck described in [12]. This vehicle is equipped with a 9-m hydraulic boom. The antennas were mounted to observe horizontal polarization. At the nominal operating height of $5 \mathrm{~m}$ with the specified field of view of the radiometers $\left(20^{\circ}\right)$, the footprint size was $1.5 \mathrm{~m}$ at a viewing angle of $10^{\circ}$ off nadir. The centers of the S- and L-band radiometers are offset by approximately $1 \mathrm{~m}$ in the installation; therefore, the centers of the ground footprints will be offset. The beams do overlap, but there is the potential for some variation in target properties in the area contributing to the two individual measurements.

In 1995, a different truck system was used [13]. Observations were made at an elevation of $8 \mathrm{~m}$, which resulted in footprints closer to $2.5 \mathrm{~m}$ for each of the sensors.

In addition to the two microwave radiometers, several other supporting instruments were also mounted on the truck platform. A small portable thermal-infrared radiometer was used to estimate the surface temperature by measuring thermal emission in the 8-14-microns wavelength range. Target location for the microwave radiometers was achieved with a color video camera installed on the platform between the two antennas. The look angle of the instrument platform was determined by an inclinometer system.

Calibration of the radiometers is based on external reference targets. The external targets typically used are sky $(\sim 5 \mathrm{~K})$ and absorber ( $\sim 300 \mathrm{~K})$. These are usually quite stable references, cover the entire range of instrument response, and are easy to obtain. Water calibration was also conducted occasionally. Water has well-known $T_{B}$ values as functions of temperature and angle. By varying the angle, reference $T_{B}$ values between 50 and $110 \mathrm{~K}$ can be obtained. Water calibration is more difficult to obtain frequently since it usually must be done at some location other than test sites.

\section{EXPERIMENT DESCRIPTIONS}

The experiments were conducted at two sites using sprinkler irrigation to apply water. In 1994, plots at the Beltsville
Agricultural Research Center (BARC), Beltsville, MD, were used. The soil was a sandy loam (70\% sand and $6 \%$ clay) with a smooth surface. Bulk density averaged $1.45 \mathrm{~g} / \mathrm{cm}^{3}$. Hydraulic conductivity was measured as $0.338 \mathrm{~cm} / \mathrm{h}$ using disc permeameters at $4-\mathrm{cm}$ tension. From this, the saturated hydraulic conductivity was estimated as $22 \mathrm{~cm} / \mathrm{h}$.

In 1995, the experiments were conducted at facilities of the University of California, Davis. Soil conditions were quite different from 1994. This was also a smooth bare soil. The soil at this location has been extensively studied [14], [15]. The particular area these measurements were conducted in was a Yolo silt loam (20\% sand and $20 \%$ clay). Bulk density was measured after irrigation as $1.4 \mathrm{~g} / \mathrm{cm}^{3}$. Some relevant soil properties reported in [15] for the 30-cm layer include the following: saturated water content $=44 \%$, saturated conductivity $=0.44 \mathrm{~cm} / \mathrm{h}$, and bulk density $=1.39 \mathrm{~g} / \mathrm{cm}^{3}$.

\section{RESUlTS AND DISCUSSION}

\section{A. Beltsville 1994}

Three sets of observations were made: September 27 (bare), October 3 (bare), and October 4 (corn). The irrigation system performed well over the bare plots, resulting in a uniform application. Total water application amounts were estimated as $4.2 \mathrm{~cm}$ on September 27 and October 3, and $2.5 \mathrm{~cm}$ on October 4. Due to problems in trying to uniformly apply water to the mature corn canopy, the corn data were not used here. Prior to September 27, there had been a rainfall event the previous night $(>2.5 \mathrm{~cm})$ that left the soil very wet at the outset of irrigation. A rainfall event on October 1 of more than $1 \mathrm{~cm}$ resulted in moderately wet conditions for the October 3 observations.

Microwave data were collected every 2 min. Figs. 1 and 2 show the $T_{B}$ versus time for the two dates. Several common features can be observed in these figures. Prior to the water application, values for both the $\mathrm{S}$ - and $\mathrm{L}$-band $T_{B}$ were constant. The S-band $T_{B}$ is slightly higher than L-band, which would be expected for a drying bare soil. Following the start of irrigation, there is a brief ( $\sim 15 \mathrm{~min})$ interval during which the 


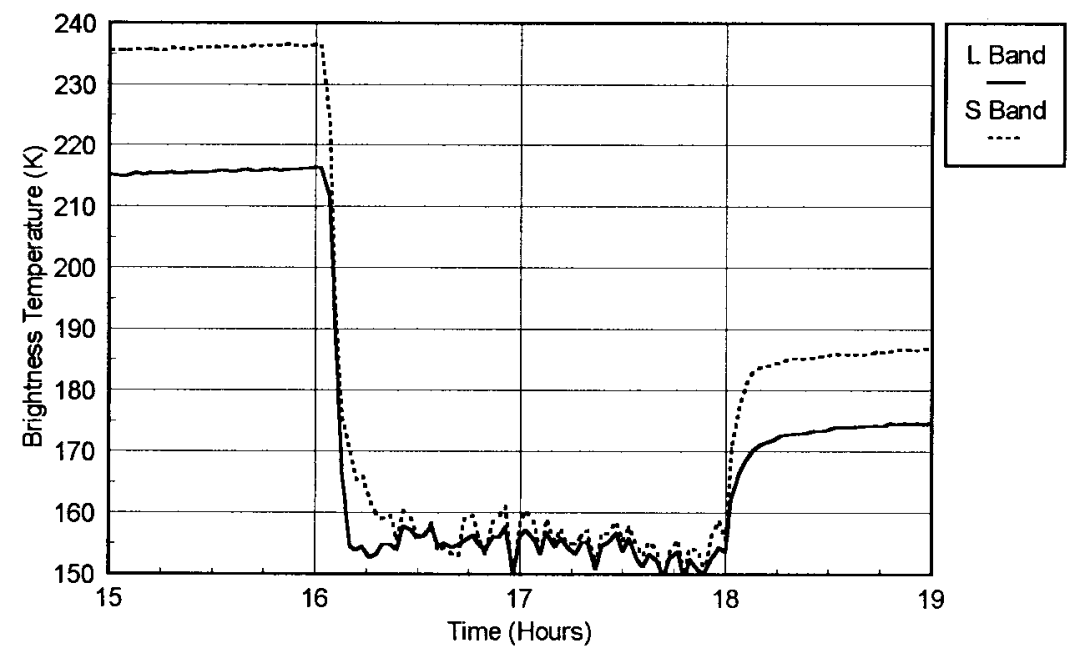

Fig. 2. Observed $T_{B}$ during and after infiltration on October 3, 1994, on a bare sandy loam soil at Beltsville.

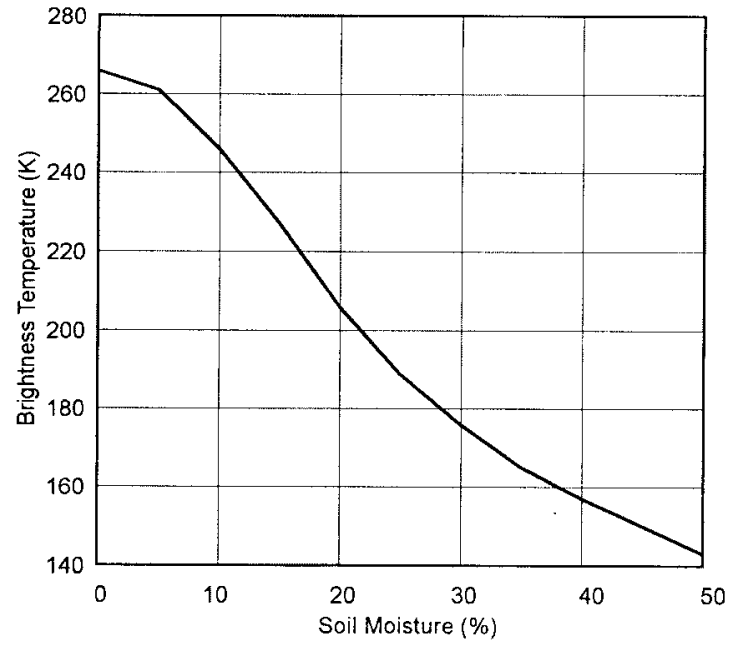

Fig. 3. Predicted relationship between $\boldsymbol{T}_{\boldsymbol{B}}$ and soil moisture for a sandy loam soil.

$T_{B}$ plunges to a new constant value for both S- and L-band. It remains at this value until the water application stops. When the irrigation ends, there is a rapid rise in $T_{B}$ followed by an extended period of much slower changes in $T_{B}$.

The level of $T_{B}$ during irrigation varies between the two bands and with date. Causes of this can be the irrigation rate and sprinkler pattern, which also varied, as well as antecedent conditions. Visual observations indicated that ponding (water pooling on the surface) did not occur. Considering the highsaturated conductivity of this soil and the relatively low water application rates possible with the sprinkler irrigation system, no ponding was expected. The minimum $T_{B}$ values observed would indicate a soil moisture close to, but not at, saturation for this soil.

Using a simple radiative transfer model that assumes that the Fresnel equation assumptions on profile homogeneity apply [16], a relationship between $T_{B}$ and soil moisture was predicted for the soil under investigation and is shown in Fig. 3. This can be used to interpret the observations in Figs. 1 and 2; the comments will focus on Fig. 2. The initial condition $T_{B}$ for L-band indicates a soil moisture of about $17 \%$. The constant value $T_{B}$ during irrigation is estimated as $155 \mathrm{~K}$ from Fig. 2. Using Fig. 3, this $T_{B}$ would result in an estimated soil moisture of $41 \%$. This soil moisture is very close to the total porosity or saturated soil moisture for this soil $(\sim 45 \%)$.

Due to the spatial offset of the centers of the two radiometers and the observed variations in surface wetness during water application, a detailed comparison of the behavior of the curves is difficult. This is especially true during the initial phases of water application.

A close examination of the $T_{B}$ curves at the end of irrigation in Fig. 2 also reveals wavelength-specific effects that reflect the differences in the contributing depth of the S- and L-bands. After the end of the irrigation, the water in the soil column should drain to the 1/3 bar tension (sometimes called field capacity) soil moisture value. Without evaporation, the soil moisture should remain at this nominal level. The results shown in Fig. 2 indicate a more rapid increase in $T_{B}$ for S-band than L-band, which would be expected because a shallower (more rapidly drying) depth contributes to the measurement at S-band. This pattern is not observed in Fig. 1. A possible explanation may be that the initially wetter conditions present for Fig. 1 produce a more uniform profile. The longer term variations include some thermal effects due to diurnal (nighttime) temperature changes.

These results show extremely interesting patterns that are obviously correlated with infiltration. Different results for different wavelengths suggest that near-surface profile information can be extracted. Unfortunately, the infiltration rates on this particular soil are very high and changes occur rapidly. Therefore, this would not be a practical solution to observing infiltration without high temporal resolution.

\section{B. Davis 1995}

1) General Observations: The soil at the Davis site was very dry prior to irrigation performed on June 12. Limited sampling indicated the following volumetric soil moisture 


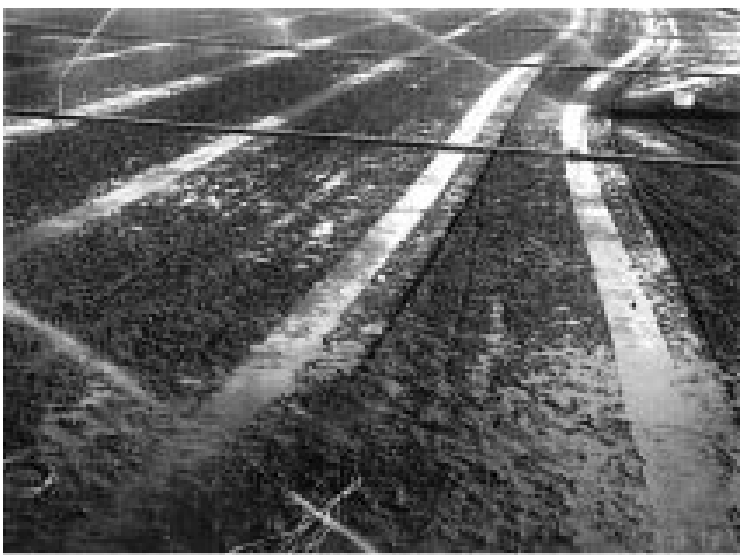

(a)

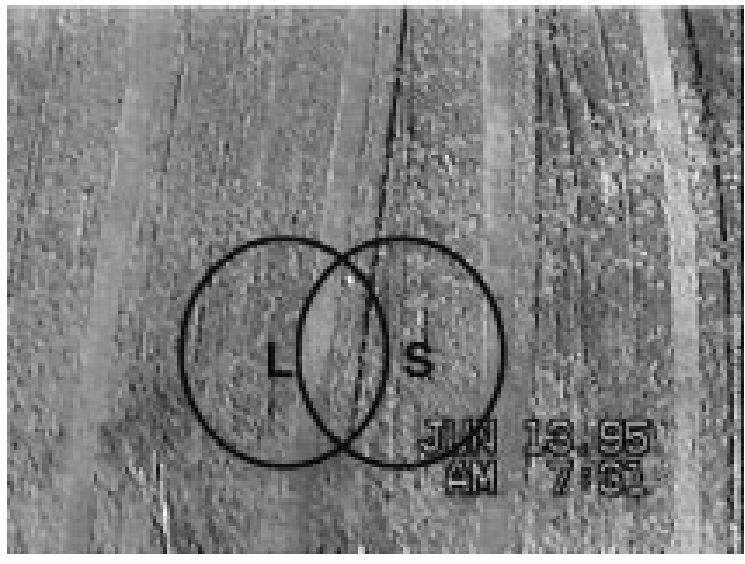

(b)

Fig. 4. Photographs of conditions at the Davis site (a) during irrigation and (b) the nominal footprint locations of the radiometers.

profile: $0-5 \mathrm{~cm} 6 \%, 5-10 \mathrm{~cm} \mathrm{11 \% ,} \mathrm{and} \mathrm{10-15} \mathrm{cm} \mathrm{19 \% .} \mathrm{Visual}$ observation of the $0-5-\mathrm{cm}$ layer indicated uniform conditions. For a silt loam soil, the 15 bar tension moisture content is on the order of $10 \%$ and the $1 / 3$ bar is on the order of $35 \%$.

Irrigation at a rate of approximately $0.5 \mathrm{~cm} / \mathrm{h}$ was initiated in the early evening to minimize losses to evaporation and blowing. In contrast to the Beltsville experiment, the irrigation rate was approximately the same as the saturated conductivity for the soil $(\sim 0.44 \mathrm{~cm} / \mathrm{h})$. There was some ponding of water on the soil surface, as illustrated in Fig. 4(a). The sensor footprints are illustrated in Fig. 4(b). It is obvious that the sensor observes what visually looks like a mixed condition of standing water and soil.

Fig. 5 shows the $T_{B}$ trace observed for S- and L-band. At the outset of irrigation, large decreases in $T_{B}$ were observed as expected. However, as time progressed, oscillation began to occur. The pattern of oscillation was similar to that which is predicted using coherent radiative transfer models [3] for a layered media having a sharp dielectric boundary.

This is the first time that coherent reflection has been observed in soil moisture studies. Previous soil related investigations designed to study coherent reflection have utilized buried plate experiments [17], [18]. In these studies, a metal plate (which has a very high reflectivity) is buried at increasing depths in a uniform soil. As the soil thickness above the plate increases, the oscillatory pattern predicted from coherent models has been observed. Since no soil moisture field experiments have ever reported this phenomenon, it has been assumed that the sharp dielectric boundaries needed to produce the effect do not occur in nature with sufficient uniformity over an area the size of a radiometer field of view.

There are several features of the coherent reflectivity that can be readily observed in Fig. 5. For an individual wavelength, the time between peaks is consistent. In addition, the magnitude of the oscillation decreases with time. Theory [3] predicts that the reflectivity will oscillate as the depth to the dielectric boundary increases and the peaks will occur at fixed depth intervals of $\left(\lambda / \epsilon_{\text {soil }}^{0.5}\right) / 2$, where $\lambda$ is the wavelength and $\epsilon_{\text {soil }}$ is the dielectric constant of the soil layer. As illustrated in Fig. 6, for L-band measurements on a wet soil (when the soil moisture is near saturation or $40 \%$ here), this oscillation interval would be on the order of $2-3 \mathrm{~cm}$. The decrease in oscillation amplitude with time (or depth) is attributed to the decreasing impact of this layer interface as it gets deeper in the soil column and approaches a depth at which the profile can be treated as uniform.

In addition to the individual wavelength behavior, the $\mathrm{S}$ - and L-band results can be compared. It appears that the time period for S-band is roughly half that of L-band and the oscillations stop sooner than for L-band. Both of these features would be expected from the coherent reflection.

2) Wetting Front Movement: Before examining the relationship between the observed and theoretical $T_{B}$ during infiltration, it is necessary to convert the observed trace from $T_{B}$ versus time to $T_{B}$ versus depth. This requires some knowledge of the rate and duration of water application. At the scale we are observing, this involves a few assumptions to offset some missing information. It is very difficult to achieve a uniform application using sprinkler irrigation; therefore, the rate and amount of water applied is a source of uncertainty. On the average, the rate of application was measured as $0.5 \mathrm{~cm} / \mathrm{h}$.

The advancement of soil wetting during infiltration is illustrated in Fig. 7, which is derived from results obtained by Bodman and Colman [19] for a Yolo silt loam soil. The curves in this figure show the moisture content as a function of depth at specific points in time during infiltration. This was a laboratory study, and the entire column was very dry with a high water application rate. The moisture profile can be subdivided into four sections: a very wet (saturated) nearsurface layer, a wet layer with a slightly lower soil moisture, a layer of rapidly changing soil moisture at the wetting front, and the initial dry soil. As part of this work, Bodman and Colman [19] attempted to evaluate soil moisture conditions at the wetting front. The authors note the difficulty in trying to measure very thin layers and were only able to achieve a minimum layer thickness of $0.5 \mathrm{~cm}$. For the Yolo silt loam, the measured moisture content of this wetting layer averaged $16.8 \%$ and remained constant as the wetting front increased in depth.

For analysis, it is necessary to set some boundaries on the wetting front location. As noted previously, the initial soil moisture in the $0-5-\mathrm{cm}$ soil layer was on the order of $6 \%$. Total porosity for a soil with a bulk density of $1.4 \mathrm{~g} / \mathrm{cm}^{3}$ would be 


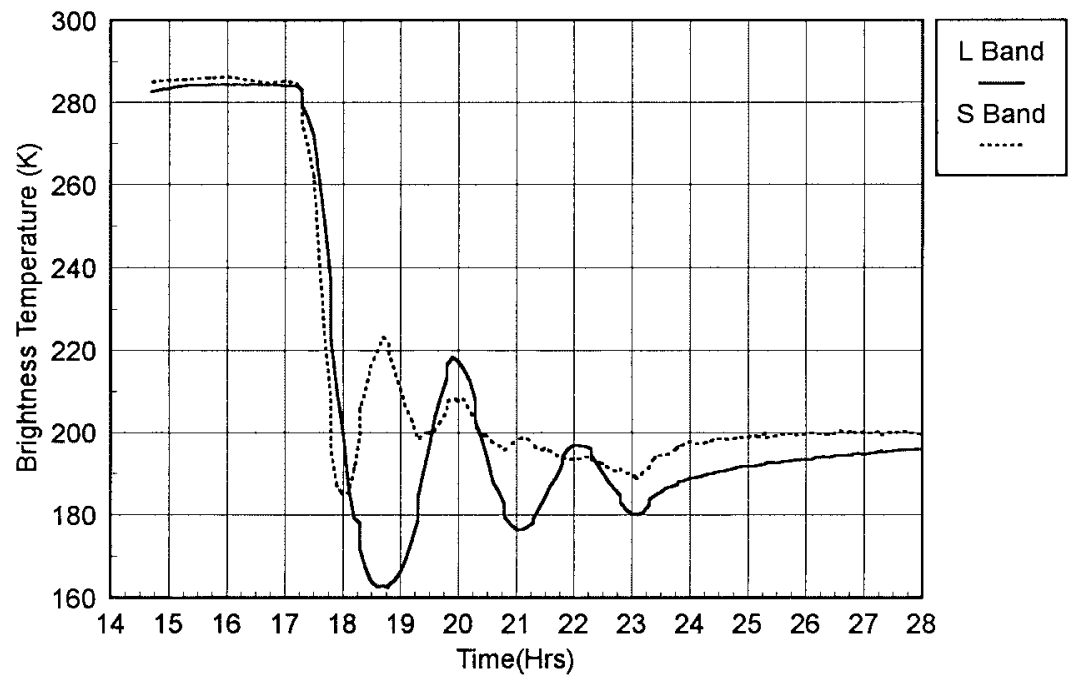

Fig. 5. Observed $\boldsymbol{T}_{\boldsymbol{B}}$ during and after infiltration on June 12, 1995, on a silt loam soil at Davis.

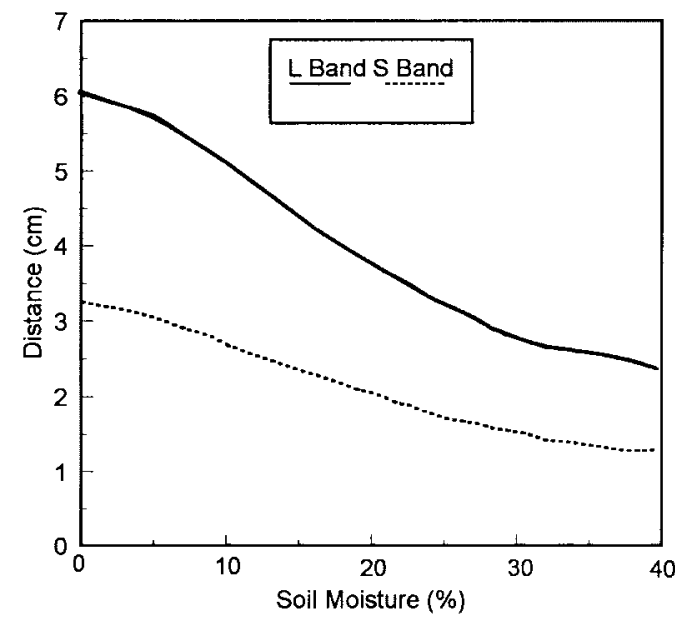

Fig. 6. Effect of soil moisture at the wetting front boundary on the distance (d) between successive minima in coherent reflectivity.

$47 \%$. The difference between these two values $(41 \%)$ is the available pore space. If all pore space was filled behind the wetting front, the depth of the wetting front at any point in time with the irrigation rate of $0.5 \mathrm{~cm} / \mathrm{h}$ would be $\left[(0.5 \mathrm{~cm} / \mathrm{h})^{*}\right.$ no. hours $] / 0.41$. This represents the minimum rate of wetting front advancement. Fig. 8 is a graph of observed $T_{B}$ versus wetting front depth under these assumptions. If the wetting behaves more like Fig. 7 with a wetting layer, the rate of the wetting front advancement could be higher since all pores would not be filled.

3) Prediction Using a Radiative Transfer Model: The coherent radiative transfer model described in [4] was used with estimates of the soil dielectric properties based on [20] to predict the $T_{B}$ as a function of the thickness of a wet soil layer over a dry soil. This particular model requires the specification of a layer structure $(0.05-\mathrm{cm}$ layers to $15 \mathrm{~cm}$ and $0.1-\mathrm{cm}$ layers between 15 and $35 \mathrm{~cm}$ ) and a set of parameters for each layer (dielectric constant and temperature).

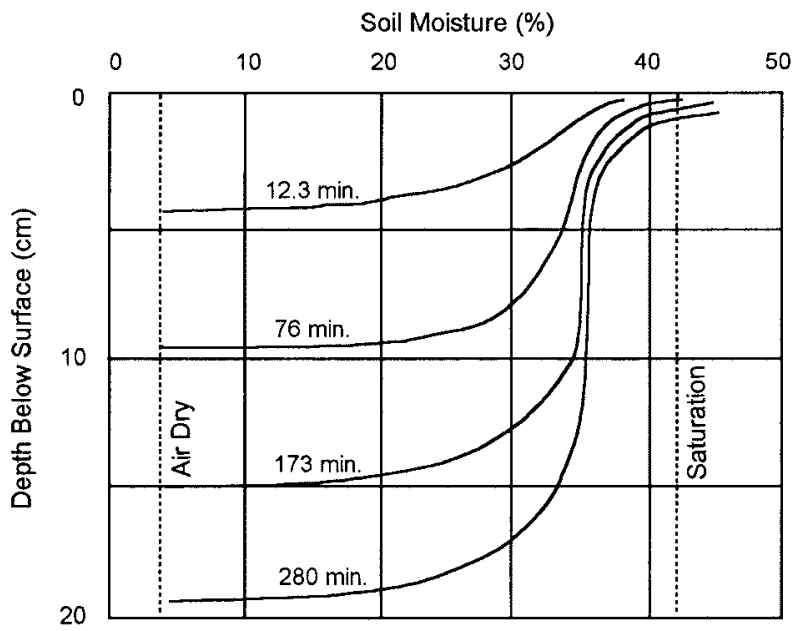

Fig. 7. Observed behavior of the soil wetting front during infiltration for a Yolo silt loam, based on data in Bodman and Colman [19].

A constant temperature of $300 \mathrm{~K}$ was used based on field observations. The typical moisture profiles shown in Fig. 7 were approximated by linear segments representing the nearly saturated surface layer, the initial dry profile, and a wetting front transition between the two. The nearly saturated surface layer was defined with a $40 \%$ soil moisture at the surface that transitioned linearly to $35 \%$ (nominally, the field capacity) at the top of the wetting front. The wetting front was defined by a linear function between $35 \%$ at the top and $6 \%$ (the measured initial soil moisture). The dielectric constants were calculated using [20] based on the soil texture and density and an assumed salinity of $2 \mathrm{ppt}$ for the soil water, which is reasonable for irrigated soils. A minimal value of 0.1 was assumed for the roughness parameter $h$ to account for the effects of surface roughness on the emission [21]. The results of the calculation are presented in Fig. 9 for the two wavelengths for a wetting front width of $1.5 \mathrm{~cm}$.

The oscillatory behavior in Fig. 9 is similar to that in the observations. The distance between adjacent minima is 


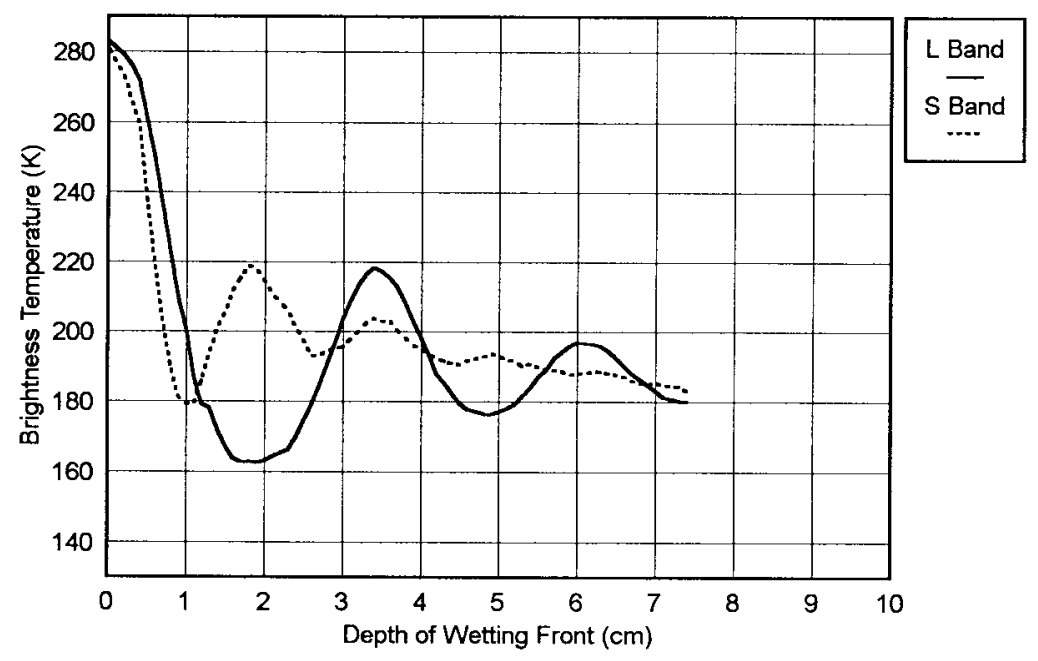

Fig. 8. Observed $\boldsymbol{T}_{\boldsymbol{B}}$ versus the predicted wetting front depth for the June 12, 1995, experiments.

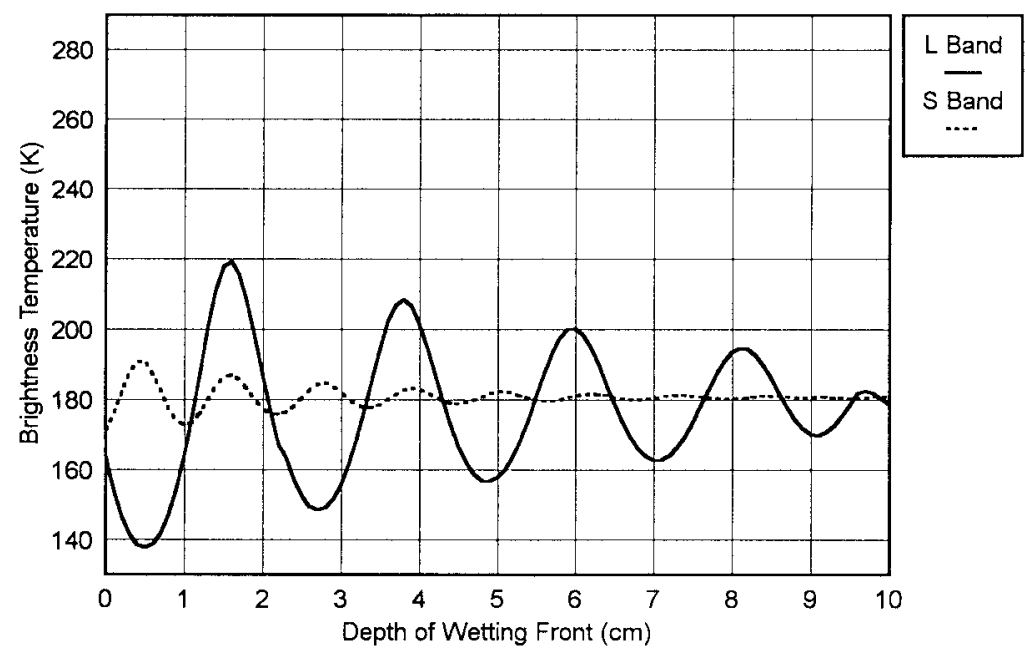

Fig. 9. Modeled values of $T_{B}$ at 21 and $11 \mathrm{~cm}$ for the case of wetting front thickness of $1.5 \mathrm{~cm}$ and salinity of 2 ppt.

about $1.2 \mathrm{~cm}$ at S-band and about $2.2 \mathrm{~cm}$ at L-band, which can be compared with Fig. 8. The amplitude of the L-band oscillations is greater in the calculations $(83 \mathrm{~K})$ than in the observations $(56 \mathrm{~K})$. At S-band, the observed and calculated amplitudes are comparable, except for the first cycle. The number of cycles is much greater in the calculations, six at S-band versus three in the observations. This is perhaps due to neglecting any variations in the thickness of the wetting front over the footprint. The fact that the period of the oscillations observed matches with the model supports the assumption that the coherent model is an adequate representation.

The sensitivity of the $T_{B}$ to the soil salinity and the thickness of the wetting front between 1 and $2 \mathrm{~cm}$ was studied. Varying the salinity had minimal effect on the results, i.e., $10-\mathrm{K}$ variation at L-band and about half that at S-band. This is because the conductivity losses due to salinity decrease with frequency. The thickness of the wetting front had a much stronger effect on the results, about $34 \mathrm{~K}$ at L-band and $43 \mathrm{~K}$ at S-band. Here the higher frequency, shorter wavelength is more strongly affected because the transition layer is a larger fraction of the wavelength. These results imply that a transition thickness of $1.5 \mathrm{~cm}$ is appropriate for this case; the calculated $T_{B}$ at L-band is greater than that observed, while it is less for S-band. The post irrigation $T_{B}$ values for both channels are in agreement with the observations, 190-195 K.

\section{SUMMARY}

Experiments were conducted using truck-based microwave radiometers to observe small plots during and following sprinkler irrigation. Data were collected using microwave radiometers operating at 1.41- (L-band) and 2.65-GHz (S-band) horizontal polarization mounted on a boom-type truck over loamy sand soil in 1994 and a silt loam in 1995. For the sandy loam soils with infiltration capabilities exceeding the water application rate, the observed $T_{B}$ quickly reached a nominally constant value during irrigation. When the irrigation was stopped, the $T_{B}$ began to increase as drainage took place. Contributing depth-related differences were observed for L- and 
S-band as expected. The irrigation rates in 1995 with the silt loam soil exceeded the saturated conductivity of the soil. During irrigation, the $T_{B}$ values exhibited a phenomenon that had not been previously observed and identified. The temporal variation in $T_{B}$ exhibited the pattern that is associated with coherent reflection. The L- and S-bands exhibited similar patterns but were not identical due to contributing depth. These results suggested the existence of a sharp dielectric boundary (wet over dry soil) that was increasing in depth with time.

The observation of the coherent reflectivity oscillation is quite unique. The fact that the observations match with the theory should be expected in principle, but it is still remarkable considering the variability in many aspects of the physical target. Since these match so well, it may be possible to infer information on the near-surface infiltration properties of the soil profile directly from the $T_{B}$ observations and the coherent model.

\section{REFERENCES}

[1] T. J. Schmugge, "Effect of texture on microwave emission from soils," IEEE Trans. Geosci. Remote Sensing, vol. GE-18, pp. 353-361, Mar. 1980.

[2] M. C. Dobson, F. T. Ulaby, M. T. Hallikainen, and M. A. El-Rayes, "Microwave dielectric behavior of wet soil-Part II: Dielectric mixing model," IEEE Trans. Geosci. Remote Sensing, vol. GE-23, pp. 35-46, Jan. 1985 .

[3] F. T. Ulaby, R. K. Moore, and A. K. Fung, "Microwave remote sensing: Active and passive," in Theory to Application, vol. III. Dedham, MA Artech House, 1986.

[4] T. T. Wilheit, "Radiative transfer in a plane stratified dielectric," IEEE Trans. Geosci. Remote Sensing, vol. GE-16, pp. 138-143, Jan. 1978.

[5] E. G. Njoku and J. Kong, "Theory for passive microwave remote sensing of near-surface soil moisture," J. Geophys. Res., vol. 82, pp. 3108-3118, 1977.

[6] T. J. Jackson and T. J. Schmugge, "Passive microwave remote sensing system for soil moisture: Some supporting research," IEEE Trans. Geosci. Remote Sensing, vol. 27, pp. 225-235, Jan. 1989.

[7] B. J. Blanchard and P. E. O'Neill, "Estimation of the hydraulic conductivity of soils with passive microwave systems," Adv. Infiltrat., ASAE, pp. 215-225, 1983.

[8] P. J. Camillo, P. E. O'Neill, and R. J. Gurney, "Estimating soil hydraulic parameters using passive microwave data," IEEE Trans. Geosci. Remote Sensing, vol. GE-24, pp. 930-936, July 1986.

[9] L. R. Ahuja, O. Wendroth, and D. R. Nielson, "Relationship between the initial drainage of surface soil and average profile saturated hydraulic conductivity," Soil Sci. Soc. Amer. J., vol. 57, pp. 19-25, 1993.

[10] N. M. Mattikalli, E. T. Engman, L. R. Ahuja, and T. J. Jackson, "Microwave remote sensing of soil moisture for estimation of profile soil property," Int. J. Remote Sensing, vol. 19, pp. 1751-1767, 1998.

[11] K. J. Hollenbeck, T. J. Schmugge, G. M. Hornberger, and J. R. Wang, "Identifying soil hydraulic heterogeneity by detection of relative change in passive microwave remote sensing observations," Water Resour. Res., vol. 32, pp. 139-148, 1996.

[12] T. J. Jackson, P. E. O'Neill, and C. T. Swift, "Passive microwave observation of diurnal soil moisture," IEEE Trans. Geosci. Remote Sensing, vol. 35, pp. 1210-1222, Sept. 1997.

[13] P. E. O'Neill, J. J. Petrella, and A. Y. Hsu, "Comparison of multifrequency truck radar and SIR-C backscatter for soil moisture estimation in Washita'94," in Proc. Int. Geosci. Remote Sensing Symp., 1995, IEEE 95CH35770, pp. 368-370.

[14] D. R. Nielsen, J. W. Biggar, and K. T. Erii, "Spatial variability of field-measured soil-water properties," Hilgardia, vol. 42, pp. 215-259, 1976.

[15] B. Buchter, P. O. Aina, A. S. Azari, and D. R. Nielsen, "Soil spatial variability along transects," Soil Technol., vol. 4, pp. 297-314, 1991

[16] T. J. Jackson, T. J. Schmugge, and E. T. Engman, "Remote sensing applications to hydrology," Hydrol. Sci. J., vol. 41, pp. 517-530, 1996.
[17] J. C. Blinn, III, J. E. Conel, and J. G. Quade, "Microwave emission from geological materials: Observations of interference effects," J. Geophys. Res., vol. 27, pp. 4366-4378, 1972.

[18] S. Paloscia, P. Pampaloni, L. Chiarantini, P. Coppo, S. Gagliani, and G. Luzi, "Multifrequency passive microwave remote sensing of soil moisture and roughness," Int. J. Remote Sensing, vol. 14, pp. 467-483, 1993.

[19] G. B. Bodman and E. A. Colman, "Moisture and energy conditions during downward entry of water into soils," in Proc. Soil Sci. Soc. Amer., 1944, vol. 8, pp. 116-122.

[20] J. R. Wang and T. J. Schmugge, "An empirical model for the complex dielectric permittivity of soils as a function of water content," IEEE Trans. Geosci. Remote Sensing, vol. GE-18, pp. 288-295, Jan. 1980.

[21] B. J. Choudhury, T. J. Schmugge, A. Chang, and R. W. Newton, "Effect of surface roughness on the microwave emission from soils," J. Geophys. Res., vol. 84, pp. 5699-5706, 1979.

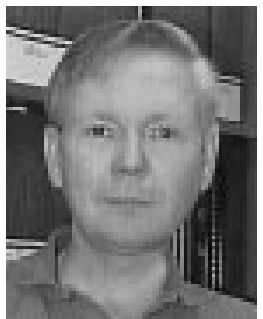

Thomas J. Jackson (A'86-SM'96) received the $\mathrm{Ph} . \mathrm{D}$. degree in civil engineering from the University of Maryland, College Park, in 1976.

$\mathrm{He}$ is a Hydrologist with the USDA Agricultural Research Service Hydrology Laboratory, Beltsville. MD. His research involves the application and development of remote-sensing technology in hydrology and agriculture. He has conducted research on the use of visible/near-infrared satellite data for deriving land cover parameters used in hydrologic models and the use of an airborne laser profiler for measuring and monitoring soil erosion. His current research focuses on the use of passive microwave techniques in hydrology. These studies have ranged from small-scale controlled condition field experiments utilizing truckmounted radiometers to large-scale multitemporal aircraft mapping.

Dr. Jackson's results of the laser profiling research resulted in a paper entitled "Airborne laser measurements of the surface topography of simulated concentrated flow gullies" (1990), which received the paper of the year award by the American Society of Agricultural Engineers. A recent paper entitled "Diurnal observations of surface soil moisture using passive microwave radiometers" was selected as the prize paper at the International Geoscience and Remote Sensing Symposium for 1994. He currently serves on the Administrative Committee of the IEEE Geoscience and Remote Sensing Society.

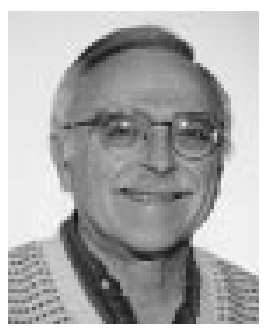

Thomas J. Schmugge (M'83-SM'91) received the B.S. degree in physics from the Illinois Institute of Technology, Chicago, in 1959 and the Ph.D degree in physics from the University of California, Berkeley, in 1965

He was with the Physics Department at Trinity College, Hartford, CT, from 1964 to 1970 . From 1971 to 1986, he was at NASA Goddard Space Flight Center, Greenbelt, MD. Currently, he is a Research Physical Scientist at the USDA Agricultural Research Service Hydrology Laboratory, Beltsville, $\mathrm{MD}$, working on the application of thermal-infrared and microwave remotesensing techniques to the study of land-surface hydrologic processes. He has worked for more than 25 years studying the use of microwave radiometers for soil moisture sensing. 


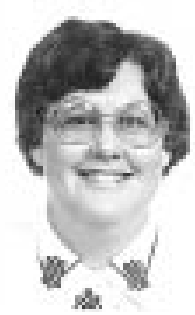

Peggy E. O'Neill (A'85) received the B.S. degree (summa cum laude) with University Honors in geography from Northern Illinois University, De Kalb, in 1976, and the M.A. degree in geography from the University of California, Santa Barbara, in 1979. She is currently pursuing the Ph.D. degree in civil and environmental engineering from Cornell University, Ithaca, NY.

She has been a Physical Scientist in the Hydrological Sciences Branch, NASA Goddard Space Flight Center, Greenbelt, MD, since 1980, where she conducts research in the dynamics of moisture storage and transfer in the soil-vegetation-atmospheric boundary layer, primarily through microwave remote-sensing techniques.

Ms. O'Neill has been a recipient of NASA Outstanding Performance and Special Achievement awards, a USDA Certificate of Appreciation, and the 1994 IGARSS Symposium Prize Paper Award (as coauthor). She has served as a member of the organizing committee and technical program committee for several international scientific conferences. She is currently a member of the IEEE Geoscience and Remote Sensing Society, American Geophysical Union, Remote Sensing Society, American Meteorological Society and its Committee on Hydrology, and International Association of Hydrological Sciences.
Marc B. Parlange received the B.S. degree in applied mathematics from Griffith University, Brisbane, Australia, in 1984 and the M.S. degree in agricultural engineering and the $\mathrm{Ph} . \mathrm{D}$. degree in civil and environmental engineering from Cornell University, Ithaca, NY, in 1987 and 1990, respectively.

He was Assistant and Associate Professor of Hydrology at the University of California, Davis, from 1990 to 1996. He then became a Professor in environmental engineering at The Johns Hopkins University, Baltimore, $\mathrm{MD}$, in 1996. He and his students work on hydrology problems related to land-atmosphere interaction, evaporation, infiltration, precipitation, and watershed modeling.

Dr. Parlange won the Macelwane Medal of the American Geophysical Union in 1997 and is currently Co-Editor of Advances in Water Resources. 